\title{
SISTEM INFORMASI AKADEMIK BERBASIS WEB PADA SMK NEGERI 2 BANYUMAS
}

\author{
1) Yustina Meisella Kristania, 2) Ina Maryani, 3) Iqbal Asyifudin \\ 1) Sistem Informasi, STMIK Nusa Mandiri Jakarta \\ yustina.yms@nusamandiri.ac.id \\ 2) Sistem Informasi, STMK Nusa Mandiri Jakarta \\ ina.maryani@nusamandiri.ac.id \\ 3) Manajemen Informatika, AMIK BSI Purwokerto \\ lqbalasy1703@bsi.ac.id
}

\begin{abstract}
Website not only can be used as a media of information dissemination, but also as a media for academic process data. With a web-based academic information systems, processing values can be done more quickly, effectively and efficiently and facilitate access for the parties concerned. SMK Negeri 2 Banyumas currently still using manual systems in the process data. This can be risky and less duplicate data provided data security. Students also can only see the value of the time of the Ascension of the class and time to see it limited. The purpose of this research is to create a website that can be used to manage the data of teachers, students and academic data. The research method used i.e. software development using models of the waterfall, observations, interviews, and the study of the literature. The website was built using programming languages HTML, PHP, CSS, Javascript and JQuery. using MySQL as database and Apache as a web server. The existence of this website, is expected to facilitate the dissemination of information, facilitate teachers in the academic process data so as to minimise the occurrence of duplicate data and data security become more assured.
\end{abstract}

\section{Keywords: Academic Information System, SMK Negeri 2 Banyumas, Website.}

Abstrak - Website tidak hanya dapat dimanfaatkan sebagai media penyebaran informasi, tetapi juga sebagai media untuk mengolah data akademik. Dengan adanya sistem informasi akademik berbasis web, pengolahan nilai dapat dilakukan dengan lebih cepat, efektif dan efisien serta dapat mempermudah akses bagi pihak-pihak yang berkepentingan.SMK Negeri 2 Banyumas saat ini masih menggunakan sistem manual dalam mengolah data. Hal ini dapat beresiko terjadi kerangkapan data dan kurang terjaminya keamanan data. Siswa juga hanya dapat melihat nilai saat kenaikan kelas dan waktu melihatnya pun terbatas. Tujuan penelitian ini adalah untuk membuat website yang dapat digunakan untuk mengelola data guru, data siswa dan data akademik. Metode penelitian yang digunakan yaitu pengembangan perangkat lunak menggunakan model waterfall, pengamatan, wawancara, dan studi pustaka. Website dibangun menggunakan bahasa pemrograman HTML, PHP, CSS, Javascript dan JQuery. Serta menggunakan MySQL sebagai database dan Apache sebagai web server. Dengan adanya website ini, diharapkan dapat memuudahkan proses penyebaran informasi, memudahkan guru dalam mengolah data akademik sehingga dapat meminimalisir terjadinya kerangkapan data keamanan data menjadi lebih terjamin.

\section{Kata Kunci: Sistem Informasi Akademik, SMK Negeri 2 Banyumas, Website.}

\section{A. PENDAHULUAN}

Kemajuan teknologi semakin memudahkan masyarakat baik individu maupun kelompok dalam melaksanakan suatu kegiatan, salah satunya dibidang komunikasi. Hadirnya telepon, radio, televisi, dan internet tentu saja memudahkan proses komunikasi. Internet telah banyak digunakan mulai dari anak-anak sampai dewasa. Berdasarkan survei yang dilakukan oleh Asosiasi Penyelenggara Jaringan Internet Indonesia (APJII) mengungkap bahwa pada tahun 2016 lalu lebih dari setengah penduduk Indonesia telah terhubung ke internet yaitu sebesar 132,7 juta orang.

Trend yang sedang berlangsung sekarang ini, hampir semua bidang kegiatan manusia dapat diproses dengan sistem online. Tak terkecuali bidang pendidikan atau sekolah yang sudah menggunakan website untuk mempermudah siswa dan guru dalam menerima informasi.

Website sekolah tidak hanya dapat dimanfaatkan sebagai media penyebaran informasi, tetapi juga sebagai media untuk mengolah data akademik. Dengan adanya sistem informasi akademik berbasis web, pengolahan nilai dapat dilakukan dengan lebih cepat, efektif dan efisien serta dapat mempermudah akses bagi pihak-pihak yang berkepentingan.

SMK Negeri 2 Banyumas saat ini masih menggunakan sistem manual dalam mengolah data akademik yaitu saat guru memasukan, 
mengubah atau menghapus nilai siswa dengan menggunakan Microsoft Excel dan ketika admin atau staf memasukan, mengubah, atau menghapus data guru, data siswa, data kelas, jadwal pelajaran, jadwal mengajar, dan data admin dengan menggunakan Microsoft Excel tentu beresiko terjadinya kerangkapan data dan kurang terjaminya keamanan data.

Selain itu dalam hal penyampaian informasi pun masih manual, seperti informasi jadwal pelajaran yaitu siswa mencatat jadwal pelajaran yang disampaikan oleh guru dengan media kertas, tentu hal tersebut kurang efektif dan dapat beresiko kehilangan data jadwal pada siswa. Informasi jadwal mengajar Guru hanya dapat dilihat di sekolah atau dicatat, dikarenakan data tersebut disimpan di komputer sekolah. informasi nilai juga manual, siswa hanya dapat melihat nilai saat kenaikan kelas dan waktu melihatnya pun terbatas.

Dengan dibuatnya website pada SMK Negeri 2 Banyumas tentu sangat membantu untuk siswa dapat melihat jadwal pelajaran dan nilai secara online, tidak lagi dicatat dan waktu melihatnya pun tidak terbatas, dapat dilihat kapanpun ketika siswa ingin melihatnya. Untuk guru juga dapat melihat jadwal mengajar secara online.

Selain memudahkan dalam hal informasi, juga dapat memudahkan guru dan staf dalam mengolah data sehingga dapat meminimalisir terjadinya kerangkapan data dan terjaminnya keamanan data. Oleh karena itu penting bagi SMK Negeri 2 Banyumas untuk beralih ke sistem informasi akademik berbasis website.

Dalam penelitian ini, penulis membatasi permasalahan pada SMK Negeri 2 Banyumas agar terfokus dan dapat memberikan pelayanan informasi dengan benar dan tepat. Dalam hal ini penulis akan membahas ruang lingkup akademik yaitu Admin terdiri dari login admin, input data admin, input data guru, input data siswa, input jadwal pelajaran, input jadwal mengajar guru, edit data admin, edit data guru, edit data siswa, edit jadwal pelajaran, edit jadwal mengajar guru, delete data admin, delete data guru, delete data siswa, delete jadwal pelajaran, delete jadwal mengajar guru. Guru terdiri dari login guru, input nilai siswa, edit nilai siswa, delete nilai siswa, melihat data guru, melihat jadwal mengajar guru. Siswa terdiri dari login siswa, melihat data siswa, melihat jadwal pelajaran, melihat nilai siswa. Visitor dapat melihat informasi yang berkaitan dengan SMK Negeri 2 Banyumas, seperti profil sekolah, sejarah sekolag, program studi, kontak dan lokasi sekolah, dan lain sebagainya.

\section{B. TINJAUAN PUSTAKA}

1. Sistem
Menurut Ludwig Von Bartalanty dalam Paryati dan Ardhana (2008:2) "sistem merupakan seperangkat unsur yang saling terikat dalam suatu antar relasi diantara unsurunsur tersebut dengan lingkungan".

Syarat-syarat sistem yaitu :

a) Sistem harus dibentuk untuk menyelesaikan tujuan.

b) Elemen sistem harus mempunyai rencana yang ditetapkan.

c) Adanya hubungan diantara elemen sistem.

d) Unsur dasar dari proses (arus informasi, energi dan material) lebih penting dari pada elemen sistem.

e) Tujuan organisasi lebih penting dari pada tujuan elemen.

\section{Informasi}

Menurut Darmawan dan Fauzi (2013:2) "Informasi merupakan hasil dari pengolahan data, akan tetapi tidak semua hasil dari pengolahan tersebut bisa menjadi informasi, hasil pengolahan data yang tidak memberikan makna atau arti serta tidak bermanfaat bagi seseorang bukanlah merupakan informasi bagi orang tersebut".

Menurut Mc.leod dalam Darmawan dan Fauzi (2013:2) mengatakan suatu informasi yang berkualitas harus memiliki ciri-ciri :

a) Akurat, artinya informasi harus mencerminkan keadaan yang sebenarnya.

b) Tepat waktu, artinya informasi itu harus tersedia atau ada pada saat informas $i$ tersebut diperlukan, tidak besok atau tidak beberapa jam lagi.

c) Relevan, artinya informasi yang diberikan harus sesuai dengan yang dibutuhkan.

d) Lengkap, artinya informasi harus diberikan secara lengkap.

\section{Sistem Informas}

Menurut Sutabri (2012:46) menyatakan bahwa Sistem Informasi adalah suatu sistem di dalam suatu organisasi yang mempertemukan kebutuhan pengolahan transaksi harian yang mendukung fungsi organisasi operasi bersifat manajerial dengan kegiatan strategi dari suatu organisasi untuk dapat menyediakan kepada pihak luar tertentu dengan laporan-laporan yang diperlukan. Sistem informasi terdiri dari komponen-komponen yang disebut blok bangunan (building block), yang terdiri dari blok masukan, blok model, blok keluaran, blok teknologi, blok basis data dan blok kendali. Sebagai suatu sistem, keenam blok tersebut masing-masing saling berinteraksi satu dengan yang lain membentuk suatu kesatuan untuk mencapai sasaran. 
Berikut adalah keenam blok bangunan (building block) diantaranya :

a) Blok masukan (input block)

b) Blok model (model block)

c) Blok keluaran (Output Block)

d) Blok teknologi (technology block)

e) Blok basis data (database block)

f) Blok kendali (control block)

4. Sistem Informasi Akademik

Sistem Informasi Akademik pada SMK Negeri 2 Banyumas yang dimaksud adalah sistem pengolahan data yang berhubungan dengan pengolahan data siswa, data guru, mata pelajaran, jadwal pelajaran, kelas, dan pengolahan nilai. Tujuan diadakanya pengolahan data sekolah yaitu memudahkan guru dan staf dalam pengolahan data akademik, menyajikan informasi penting, serta menyimpan dokumen-dokumen sekolah.

\section{Website}

Menurut Puspitosari (2010:1) "website adalah halaman informasi yang disediakan melalui jalur internet sehingga bisa diakses di seluruh dunia, selama terkoneksi dengan jaringan internet".

\section{Web Server}

Menurut WK (2011:16) "Web Server merupakan perangkat lunak pada server yang memiliki fungsi sebagai penerima permintaan (request) yang berupa halaman web dari client dan mengirim kembali (respons) hasil yang diminta dalam bentuk halaman-halaman web".

\section{Web Browser}

Menurut Limantara (2009:1) "Web Browser adalah aplikasi perangkat lunak yang memungkinkan penggunanya untuk berinteraksi dengan teks, image, video, games dan informasi lainnya yang berlokasi pada halaman web pada World Wide Web (WWW) atau Local Area Network (LAN)"

8. Bahasa Pemrograman

Bahasa pemrograman merupakan Bahasa atau script yang digunakan untuk membuat sebuah website. Dalam pembuatan website pada SMK Negeri 2 Banyumas penulis menggunakan Bahasa pemrograman diantaranya :
a) HTML (Hypertext Markup Language)
b) CSS (Cascade Style Sheet)
c) PHP (PHP Hypertext Preprocessor)
d) JavaScript
e) JQuery

9. Basis Data

Menurut Simarmata (2007:1) "Basis Data adalah suatu aplikasi terpisah yang menyimpan suatu koleksi data. Masing-masing basis data memiliki satu API atau lebih yang berbeda untuk menciptakan, mengakses, mengelola, mencari, dan mereplikasi data."

$$
\text { a) MySQL }
$$

Menurut Kadir (2008:348) menyatakan bahwa MySQL adalah salah satu jenis database server yang sangat terkenal. Kepopulerannya disebabkan MySQL menggunakan SQL sebagai Bahasa dasar untuk mengakses databasenya. Selain itu, ia bersifat open source (anda tidak perlu membayar untuk menggunakannya) pada berbagai platform (kecuali untuk jenis enterpris, yang bersifat komersial). MySQL termasuk jenis rdbms (relational database management system). Itulah sebabnya istilah seperti tabel, baris dan kolom digunakan pada MySQL. Pada MySQL, sebuah database mengandung satu atau sejumlah tabel. Tabel terdiri atas sejumlah baris dan setiap baris mengandung satu atau beberapa kolom.

b) PHPMyAdmin

Menurut Zaki dan Smitdev (2008:97) "PHPMyAdmin adalah MySQL client yang berupa aplikasi web dan umumnya tersedia di server php seperti XAMPP maupun server komersial lainnya." Di web server local, anda dapat mengakses PHPMyAdmin menggunakan URL

c) XAMPP

Menurut Aryanto (2016:4) "XAMPP merupakan sebuah aplikasi perangkat lunak pemrograman dan database yang di dalamnya terdapat berbagai macam aplikasi pemrograman seperti : Apache HTTP server, MYSQL, database, Bahasa pemrograman PHP dan perl."

10. Struktur Navigasi

Dalam pembuatan website, beberapa desainer web menggunakan teknik yang biasa seperti dalam pengembangan multimedia pada umumnya. Dalam pengembangan web, terdapat beberapa model navigasi dasar yang harus dikenal dengan baik oleh desainer. Sutopo (2007:5). Model navigasi yang penulis gunakan dalam pembuatan website ini yaitu:

a) Linear Navigation Model linear navigation model digunakan oleh sebagian besar website. Informasi diberikan secara sekuensial dimulai dari satu halaman. Beberapa desainer menggunakan satu halaman untuk masuk atau keluar dari website.

b) Hierarchical Model Hierarchical model diadaptasi dari topdown desain. Konsep navigasi ini dimulai dari satu node yang menjadi homepage. Dari homepage dapat dibuat beberapa cabang ke halaman- 
halaman utama. Apabila diperlukan, dari tiap halaman utama dapat dikembangkan menjadi beberapa cabang lagi. Hal ini seperti struktur organisasi dalam perusahaan.

c) Spoke-And-Hub Model

Spoke-and-hub model hanya menggunakan satu node untuk berhubungan dengan node lain. Pada model ini hanya terdapat dua macam link yaitu dari homepage ke halaman tertentu dan dari halaman tersebut ke kembali ke homepage.

d) Full Web Model

Full web model memberikan kemampuan hyperlink yang banyak. Full web model banyak digunakan karena user dapat mengakses semua topik dengan subtopik dengan cepat. Namun kelemahan dari model ini, yaitu dapat berakibat user kehilangan cara untuk kembali ke topik sebelumnya.

11. ERD (Entity Relationship Diagram)

Fathansyah (2007:79) menyatakan bahwa "model entity-relationship yang berisi komponen-komponen himpunan entitas dan himpunan relasi yang masing-masing dilengkapi dengan atribut-atribut yang mempresentasikan seluruh fakta dari 'dunia nyata' yang kita tinjau, dapat digambarkan dengan lebih sistematis dengan menggunakan Diagram-Entity-Relationship (Diagram E-R)."

\section{LRS (Logical Record Structure)}

Menurut Kusrini dalam Nugraha dan Octasia (2016:294) "LRS (Logical Record Structure) merupakan representasi dari struktur record-record pada tabel-tabel yang terbentuk dari hasil relasi antar himpunan entitas pada diagram E-R".

\section{METODE PENELITIAN}

Metode pengembangan perangkat lunak ini menggunakan model waterfall menurut Rosa dan Salahudin (2013:28) yang terbagi menjadi lima tahapan :

1. Analisa Kebutuhan Perangkat Lunak

Pada web ini nanti akan berisi tentang siswa, guru dan admin. Pada halaman utama berisikan informasi tentang sekolah seperti profil sekolah, visi misi sekolah, dan lain sebagainya. Untuk siswa login terlebih dahulu agar dapat masuk ke halaman siswa agar dapat melihat jadwal pelajaran dan nilai. Guru juga memerlukan akses login agar dapat masuk ke halaman guru untuk melihat jadwal mengajar guru, jadwal pelajaran siswa, dan mengolah nilai siswa. Sama seperti halnya siswa dan guru, adminpun memerlukan akses login untuk masuk ke halaman admin untuk menambah, mengedit, dan menghapus data akademik.

2. Desain

Pada tahapan desain ini penulis menggunakan Adobe Dreamweaver CS6 untuk mendesain tampilan antar muka web. XAMPP atau phpMyAdmin untuk mendesain database.

3. Pembuatan Kode Program

Bahasa pemrograman yang penulis gunakan dalam pembuatan web adalah Hyper Text Markup Languange (HTML), PHP Hypertext Prepocessor (PHP), Case cading Style Set (CSS), Javascript, dan JQuery diketikan pada Adobe Dreamweaver CS6. Kemudian MySQL pada phpMyAdmin.

\section{Pengujian}

Penulis melakukan pengujian dengan metode Black Box Testing. Dengan metode ini pengujian fokus pada perangkat lunak dari segi fungsional dan memastikan semua bagian telah di uji. Dimaksudkan untuk meminimalisir terjadinya kesalahan (error) dan untuk mengetahui apakah fungsi-fungsi masukan dan keluaran sesuai dengan yang dibutuhkan.

5. Pendukung (Support) atau Pemeliharaan (Maintenance)

Pada tahap ini untuk mendukung atau memelihara sebuah web selalu melakukan update dan back-up database secara berkala, merawat hardware dan software yang digunakan, serta menerima, mengevaluasi kritik dan saran dari pengunjung web.

Teknik pengumpulan data yang digunakan dalam penelitian ini adalah:

1. Pengamatan (Observasi)

Pada metode ini penulis melakukan pengamatan langsung pada SMK Negeri 2 Banyumas terhadap permasalahan yang diambil dengan mendatangi sekolah secara langsung untuk melihat, mencatat, dan mengambil foto.

\section{Wawancara (Interview)}

Penulis melakukan wawancara kepada pihak SMK Negeri 2 Banyumas secara langsung berkaitan dengan pengolahan data akademik seperti data siswa, data guru, jadwal, dan nilai untuk melengkapi data-data yang penulis perlukan.

\section{Studi Pustaka}

Pada metode study pustaka, penulis mencari, membaca, dan mempelajari informasi melalui beberapa media buku dan internet yang berhubungan dengan permasalahan dalam penulisan ini.

\section{HASIL DAN PEMBAHASAN}

1. Analisa Kebutuhan Pengguna

a) Kebutuhan Admin

1) Admin membutuhkan login untuk masuk ke halaman admin 
2) Admin membutuhkan input, edit, delete untuk mengolah data admin

3) Admin membutuhkan layanan input, edit, delete data guru

4) Admin membutuhkan layanan input, edit, delete data siswa

5) Admin membutuhkan layanan input, edit, delete jadwal

6) Admin membutuhkan layanan input, delete testimoni

7) Admin membutuhkan layanan input, delete buku tamu

8) Admin membutuhkan layanan input, edit, delete kalender akademik

9) Admin membutuhkan layanan input, edit, delete profil sekolah

10) Admin membutuhkan layanan input, edit, delete agenda

11) Admin membutuhkan input, edit, delete artikel

layanan

b) Kebutuhan Guru

1) Guru membutuhkan login untuk masuk ke halaman guru

2) Guru membutuhkan layanan untuk dapat melihat jadwal mengajar guru

3) Guru membutuhkan layanan untuk dapat melihat data siswa

4) Guru membutuhkan layanan input, edit, delete data nilai

5) Guru membutuhkan layanan update untuk memperbaharui data pribadi guru

c) Kebutuhan Siswa

1) Siswa membutuhkan login untuk masuk ke halaman siswa

2) Siswa membutuhkan layanan untuk dapat melihat jadwal pelajaran

3) Siswa membutuhkan layanan untuk dapat melihat nilai

4) Siswa membutuhkan layanan untuk dapat melihat kalender akademik

5) Siswa membutuhkan layanan update untuk memperbaharui data pribadi siswa

d) Kebutuhan Pengguna (visitor)

a. Pengguna membutuhkan layanan untuk dapat melihat profil sekolah

b. Pengguna membutuhkan layanan untuk dapat melihat agenda sekolah

c. Pengguna membutuhkan layanan untuk dapat melihat artikel sekolah

d. Pengguna membutuhkan input untuk memasukan data testimoni

e. Pengguna membutuhkan input untuk memasukan data buku tamu f. Pengguna membutuhkan layanan live chat untuk dapat berinteraksi secara online kepada admin sekolah

2. Analisa Kebutuhan Sistem

a) Pengolahan Data

1) Data Profil Sekolah yang berupa sejarah sekolah, visi dan misi.

2) Data siswa yang berupa data diri siswa

3) Data guru yang berupa data diri guru

4) Data nilai yang berupa nilai siswa

5) Data testimoni yang berupa pesan dari pengguna ke admin

6) Data jadwal yang berupa jadwal pelajaran, jadwal mengajar guru

b) Hak Akses

1) Admin

(a) Admin dapat melakukan login untuk masuk ke halaman admin

(b) Admin dapat melakukan input, edit, delete data admin

(c) Admin dapat melakukan input, edit, delete data guru

(d) Admin dapat melakukan input, edit, delete data siswa

(e) Admin dapat melakukan input, edit, delete data jadwal

(f) Admin dapat melakukan input, delete testimoni

(g) Admin dapat melakukan input, edit, delete buku tamu

(h) Admin dapat melakukan input, edit, delete profil sekolah

(i) Admin dapat melakukan input, edit, delete agenda

(j) Admin dapat melakukan input, edit, delete artikel

(k) Admin dapat melakukan input, edit, delete kalender akademik

2) Guru

(a) Guru dapat melakukan login untuk dapat masuk ke halaman guru

(b) Guru dapat melakukan input, edit, delete data nilai

(c) Guru dapat melihat jadwal mengajar guru

(d) Guru dapat melihat data siswa

(e) Guru dapat melakukan update data pribadi guru

3) Siswa
(a) Siswa dapat melakukan login untuk dapat masuk ke halaman siswa
(b) Siswa dapat melihat jadwal pelajaran
(c) Siswa dapat melihat nilai 
(d) Siswa dapat melihat kalender akademik

(e) Siswa dapat melakukan update data pribadi siswa

4) Pengguna (visitor)

(a) Pengguan dapat melihat profil sekolah

(b) Pengguan dapat melihat agenda

(c) Pengguan dapat melihat artikel

(d) Pengguan dapat melakukan input data testimoni

(e) Pengguan dapat melakukan input data buku tamu

(f) Pengguan dapat melakukan live chat ke admin

c) Security

1) Menggunakan username dan password untuk akses login setiap akan memasuki halaman pengguna.

2) Menggunakan enkripsi pada semua password.

3. Implementasi

a) Implementasi Rancangan Halaman Visitor

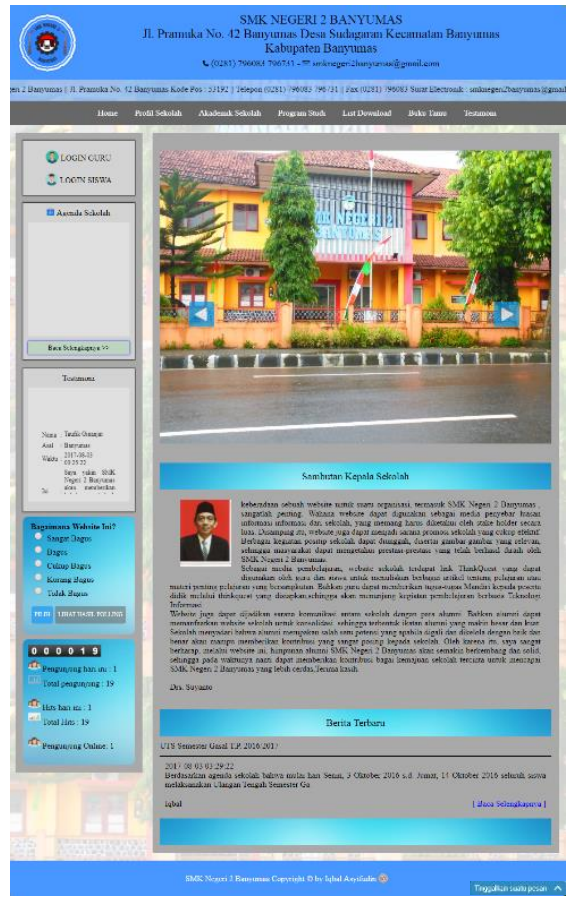

Gambar 1. Implementasi Halaman Visitor

b) Implementasi Rancangan Halaman Siswa

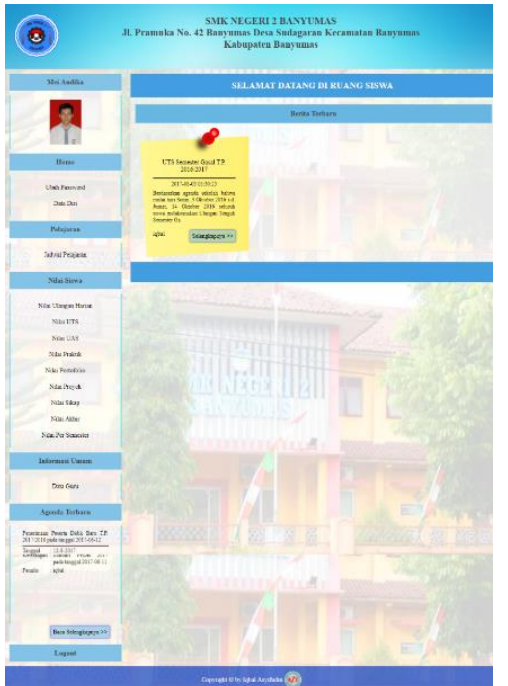

Gambar 2. Implementasi Halaman Siswa

c) Implementasi Rancangan Halaman Guru

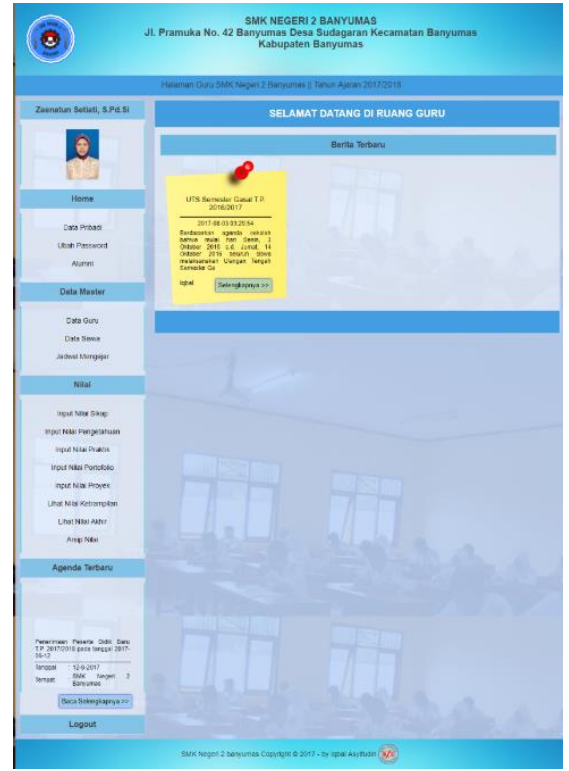

Gambar 3. Implementasi Halaman Guru 


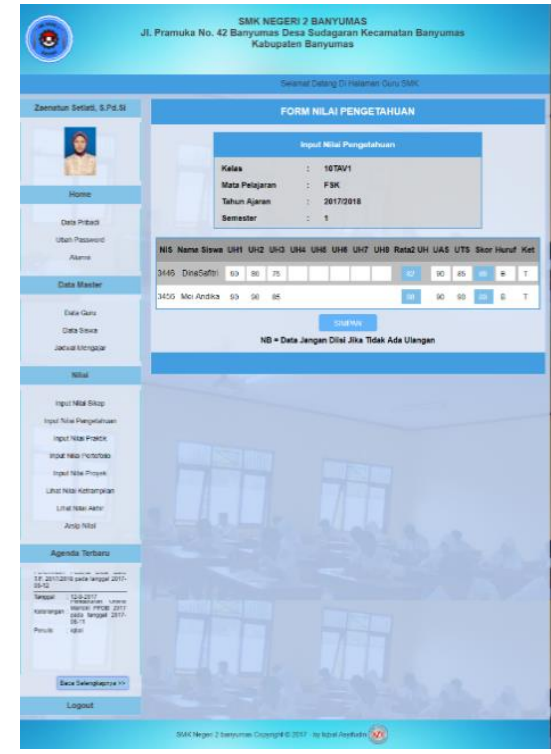

Gambar 4. Implementasi Halaman Input Nilai

4. Spesifikasi Sistem Komputer

Dalam implementasi website Sistem Informasi Akademik pada SMK Negeri 2 Banyumas harus didukung dengan adanya perangkat keras dan perangkat lunak yang digunakan agar sistem dapat berjalan dengan baik.

a) Spesifikasi Perangkat Keras

1) Server
(a) Processor : Intel $\AA$ Core ${ }^{T M} 2$ CPU 6420@2.1GHz(2C
(b) RAM PUs), 2.1GHz
(c) Mouse 2048MB / 2GB
(d) Keyboard : Optical Mouse
(e) Monitor : 104 Key : Dengan resolusi layer minimum 1024x768, 14 incs
(f) Koneksi : Minimum kecepatan akses internet 2 Mbps

2) Client TM 2 CPU 6420@2.1GHz(2CPUs), 2.1G
(a) Processor
: Intel @ Core $\mathrm{Hz}$
(b) RAM : 2048MB / 2GB
(c) Mouse : Optical Mouse
(d) Keyboard : 104 Key
(e) Monitor : Dengan resolusi layer minimum 1024x768, 14 incs
(f) Koneksi : Minimum kecepatan akses internet 2 Mbps

b) Spesifikasi Perangkat Lunak 1) Server
(a) Sistem Operasi : Windows 7 Enterprise
(b) Web Server : MySQL
(c) Web Browser : Google Chrome, Mozila Firefox.
2) Client
(a) Sistem Operasi : Windows
(b) Web Browser : Google Chrome, Mozila Firefox.

\section{Pengujian Unit}

Pengujian unit dimaksudkan untuk memastikan system yang telah dirancang sesuai dengan harapan atau tidak. Pada tahap ini penulis menggunakan metode Black Box Testing.

\section{E. KESIMPULAN DAN SARAN}

1. Kesimpulan

a) Sistem Informasi Akademik berbasis web pada SMK Negeri 2 Banyumas menggunakan Bahasa Pemrograman HTML, PHP, CSS, Javascript, JQuery.

b) Pengguna website ini dikelompokan menjadi 4 user, antara lain : admin, guru, siswa dan visitor.

c) Sistem Informasi Akademik berbasis web pada SMK Negeri 2 Banyumas dapat membantu guru dalam proses pengolahan nilai.

d) Sistem Informasi Akademik berbasis web dapat mempermudah siswa dalam memperoleh informasi seputar sekolah. Seperti nilai, jadwal pelajaran dan kalender akademik.

e) Website SMK Negeri 2 Banyumas dapat menjadi media promosi kepada masyarakat.

2. Saran

a) Jika kedepanya website ini akan dikembangkan dapat ditambahkan fitur seperti : guru dapat memberi tugas kepada siswa melalui website dan elearning.

b) Sebaiknya data website selalu diperbaharui, agar informasi yang disajikan selalu uptodate.

c) Sebaiknya admin selalu membackup data secara berkala.

d) Sebaiknya website selalu dikelola oleh tenaga IT yang handal.

\section{DAFTAR PUSTAKA}

[1] A.S., Rosa, M. Shalahuddin. 2014. Rekayasa Perangkat Lunak. Bandung: Informatika.

[2] Aryanto. 2016. Pengolahan Database MySQL. Yogyakarta: CV. Budi Utama. 
[3] Darmawan, Deni, dan Kunkun Nur Fauzi. 2013. Sistem Informasi Manajemen. Bandung: PT. Remaja Rosdakarya.

[4] Fathansyah. 2007. Basis Data. Bandung: Informatika.

[5] Kadir, Abdul. 2008. Dasar Pemrograman Web Dinamis Menggunakan PHP. Yogyakarta: CV. Andi Offset.

[6] Komputer, Wahana. 2011. Mastering CMS Programming With PHP \& MySQL. Yogyakarta: CV. Andi Offset.

[7] Limantara, Hans S. 2009. Jelajah Dunia Maya Dengan Cepat Dan Mudah. Jakarta: PT. Elex Media Komputindo.

[8] Nugraha, Aditya, dan Anita Octasia. 2016. Sistem Informasi Penjualan Kaos Berbasis Web Pada Distro Sickness Berbasis ECommerce. ISBN:978-602-72850-3-3. Seminar Nasional IImu Pengetahuan dan Teknologi Komputer Nusa Mandiri . Diambil Dari: http://konferensi.nusamandiri.ac.id/prosidi ng/index.php/sniptek/article/view/68/67

[9] Paryati, dan Yosef Murya. KA. 2008. Sistem Informasi. Yogyakarta: Ardana Media.

[10] Puspitosari, Heni A. 2010. Membangun Website Interaktif dengan Adobe Creative Suite 5. Yogyakarta: PT. Skripta Media Creative.

[11] Simarmata, Janner. 2007. Perancangan Basis Data. Yogyakarta: CV. Andi Offset.

[12] Sutarbi, Tata. 2012. Konsep Sistem Informasi. Yogyakarta: CV. Andi Offset.

[13] Sutopo, Ariesto Hadi. 2007. Pemrograman Flash dengan PHP \& MySQL. Yogyakarta: Penerbit Andi.

[14] Zaki, Ali, dan Smitdev Community. 2008. PHP dan MySQL. Jakarta: PT. Elex Media Komputindo. 